\title{
Configuración epistémica de la pedagogía. Tendencias que han proliferado en la historia de la educación ${ }^{1}$
}

\author{
Epistemic configuration of pedagogy. \\ Widespread trends in the history of education \\ Configuração epistémica da pedagogia. \\ Tendências que proliferaram na história da educação.
}

\author{
Alexander Ortiz Ocaña ${ }^{2}$ \\ Universidad de Magdalena (Colombia)
}

Recepción: 13/04/2017

Evaluación: 24/06/2017

Aceptación: 24/08/2017

Artículo de Revisión

DOI: https://doi.org/10.19053/01227238.7570

\section{RESUMEN}

En este artículo se hace una revisión reflexión sobre la educación. Se considera temática reflexiva que permite analizar a la pedagogía como la constelación la génesis, evolución, y configuración universal del saber pedagógico epistémica de la pedagogía, valorando configurado por la comunidad académica las principales tendencias que han internacional. Sin embargo, aún está proliferado en la historia de la educación. Se identifican cinco tendencias $u$ orientaciones epistemológicas: la pedagogía como ciencia de la educación, la pedagogía como una de las ciencias de la educación, la pedagogía como saber pedagógico, la pedagogía como arte de enseñar (didáctica), y la pedagogía como vigente el controversial debate sobre la pedagogía y las ciencias de la educación. No hay consenso en la comunidad académica internacional sobre la configuración epistémica de la pedagogía. Las concepciones y criterios dependen de las particularidades de esta ciencia o disciplina en cada país. En Colombia la

1 Resultado del proyecto Escenarios formativos mediadores de la biopraxis de niños y niñas en contexto de pobreza, financiado por la Universidad del Magdalena. Santa Marta. Colombia. Grupo GIEDU: Epistemología Configurativa y Educación Decolonial.

2 Doctor en Ciencias de la Educación. Docente de planta de tiempo completo de la Universidad del Magdalena. Santa Marta. Colombia. Investigador Senior de Colciencias. Investigador del Doctorado en Ciencias de la Educación RUDECOLOMBIA. Grupo Epistemología Configurativa y Educación Decolonial (Categoría A1 en Colciencias). Email: alexanderortiz2009@gmail.com 
pedagogía es un saber pedagógico o una reflexión sobre la educación, en Cuba la pedagogía es considerada la ciencia que estudia la educación, en Estados Unidos se habla de la Ciencia de la Educación, en singular, pero no se utiliza la noción de pedagogía con la connotación de ciencia de la educación. Asimismo, en Francia se habla de las Ciencias de la Educación, en plural, y en Alemania la Pedagogía es entendida como la Ciencia de la Educación. Se concluye que la pedagogía no debe ser considerada un campo, sino una configuración conceptual comprensiva.

Palabras clave: pedagogía; educación; ciencias de la educación; saber pedagógico; enseñanza; Revista Historia de la Educación Latinoamericana.

\section{ABSTRACT}

This article carries out a reflexive thematic review that allows to analyze the genesis, evolution, and epistemic configuration of the pedagogy by evaluating the main tendencies that have widespread in the history of education. Five tendencies or epistemological orientations are identified: pedagogy as a science of education, pedagogy as one of the sciences of education, pedagogy as pedagogical knowledge, pedagogy as the art of teaching (didactics), and pedagogy as a reflection on the education. Pedagogy is considered as the universal constellation of pedagogical knowledge configured by the international academic community. However, the controversial debate on pedagogy and the education sciences is still in force. There is no consensus within the international academic community about the epistemic configuration of pedagogy. The conceptions and criteria depend on the particularities of this science or discipline in each country. In Colombia, pedagogy is a pedagogical knowledge or a reflection on education; in Cuba, pedagogy is considered the science that studies education; in the United
States it is the Science of Education, in singular, but it is not used the notion of pedagogy with the connotation of education science. Also, in France, they refer to the Sciences of the Education, in plural, and in Germany, the Pedagogy is understood as the Science of Education. It is concluded that pedagogy should not be considered as a field, but a comprehensive conceptual configuration.

Keywords: pedagogy; education; education sciences; pedagogical knowledge; teaching; Journal History of Latin American Education.

\section{RESUMO}

Neste artigo se faz uma revisão temática reflexiva que permite analisar a gênese, evolução e configuração epistêmica da pedagogia, avaliando as principais tendências que proliferaram na história da educação. Identificam-se cinco tendências e orientações epistemológicas: a pedagogia como ciência da educação, a pedagogia como uma das ciências da educação, a pedagogia como saber pedagógico, a pedagogia como arte de ensinar (didática), e a pedagogia como reflexão sobre a educação. Considera-se a pedagogia como a constelação universal do saber pedagógico configurado pela comunidade acadêmica internacional. Todavia, ainda esta vigente o controverso debate sobre a pedagogia e as ciências da educação. Não há consenso na comunidade acadêmica internacional sobre a configuração epistêmica da pedagogia. As concepções e critérios dependem das particularidades desta ciência ou disciplina em cada país. $\mathrm{Na}$ Colômbia, a pedagogia é um saber pedagógico ou uma reflexão sobre a educação, em Cuba a pedagogia é considerada a ciência que estuda a educação, nos Estados Unidos se fala em Ciência da Educação, no singular, porém não se utiliza a noção de pedagogia com a conotação de ciência da educação. Assim mesmo, na França se fala de Ciências da Educação, no plural, e na Alemanha a 
Pedagogia é entendida como a Ciência da Educação. Conclui-se que a pedagogia não deve ser considerada um campo, senão uma configuração conceitual compreensiva.

Palavras-chave: pedagogia; educação; ciências da educação; saber pedagógico; ensino; Revista História da Educação Latinoamericana.

Contextualización: Idioma Maya Tzútujil

Contextualizador: Salvador Quiacaín Rocch'e.

Ministerio de Educación de Guatemala

\section{RULUTZ'UXIIK}

Joo' ruwach rucholiik tz'atoon ja nimaq taq na'ooj rixiin ja runa'ojiltijoneem: Nab'eey. Ja na'b'altijoneem jaari runa'ojiil ja tijoneem. Ruuk'aab'. Ja na'b'altijoneem jun chi re na'ojiil rixiin ja rijoneem. Roox. Ja nab'altijoneem jaari na'ooj rixiin ojtaqineem. Ruukaaj. Ja na'b'altijoneem jaari ja sak'ajiil rixiin ja k'utuneem. Roo'. Ja na'b'altijoneem jaari ja ch'ab'ooj rixiin ja ojtaqineem.

Xchob'otaji chi ja na'b'altijoneem jaari ja jun wi'aaj rixiin ja na'ooj rixiin na'b'altijob'al nuuk'aan kumaal ja ruwinaqiil ninaq taq tijoneem chi paan ja ruwach'uleew. Xar waari, k'a k'o na rutzijoxiik ja na'b'altijoneem ruk'iin ja etamab'aliil rixiin ojtaqineem. Ma k'o ta k'amori'iil kuk'iin ja ruwinaqiil ja ninaq taq tijoneem chi paan ja ruwach'uleew, chi riij runuk'iik ja runa'ojiiltijoneem ja na'b'altijoneem.

K'iy ja na'ojiil, xar waari k'ooli ja rujalab'en rii' chi rujun junaal ja rixiin awa etamab'aliil ri', chi paanja tinaamit eje'e. Ja kolonb'iya, ja na'b'altijoneem jaari' jar ojtaq na'b'altijoneem owi jun ch'ob'ooj chi riij ja ojtaqineem, jar Estat'os Unidos ntzijox riij ruwach chi jar Etamab'aliil rixiin ja tijoneem, pa rujunaal, xar waari ma ti kooji ja tziij na'ab'atijoneem ruk'iin ja etamab'aliil.

Keeri Prancia, ntzijoxi jar etamab'aliil rixiin jar ojtaqineem, pa ruk'iyaal, ja k'ar Alemaya ja na'b'altijoneem ch'otajnaq, chi jaari ja ejetamab'al rixiin ja ojtaqineem. Xch'ob'ataji chi ja na'b'altijoneem ma jun nimalaj etamab'aliil ta, jun nuk'uneem ja qas q'alaaj riij ruwach chik.

Taq tziij nk'atziini: na'b'altijonee; ojtaqineem; ejtamb'allil rixiin ja ojtaqineem; ojtaq rixiin na'b'altinoneem, $k^{\prime} u$ tuneem. Ruuwuuj ruk'asalemaal ojtaqineem pa Latino'ametika.

\section{INTRODUCCIÓN}

El concepto de pedagogía, el tema pedagógico y la pedagogía como ciencia, disciplina, saber o reflexión, han sido estudiados por múltiples autores en todos los continentes. Destacan en este abordaje las tradiciones de Alemania, Francia, Estados Unidos y Latinoamérica. Las concepciones sobre la pedagogía que se han venido configurando a lo largo de la historia de la educación difieren en las diversas regiones y países. Es por ello que un análisis minucioso, detallado y profundo de la configuración epistémica de la noción de pedagogía requiere tener en cuenta no solo la propia dimensión epistémica de la misma sino además su dimensión geográfica. 
Es conocido que las primeras reflexiones sistematizadas, armónicas y coherentes sobre lo educativo y lo pedagógico emergen en las obras de Comenio $^{3}$, Rousseau ${ }^{4}$, Pestalozzi $^{5}$ y Herbart ${ }^{6}$. En la pedagogía alemana, además de los aportes originarios de Herbart, encontramos los trabajos de Kant ${ }^{7}$, Natorp ${ }^{8}$, Dilthey ${ }^{9}{ }^{10}$, Simmel $^{11}$, Luhmann ${ }^{12}$ y Luhmann \& Schorr ${ }^{13}{ }^{14}$. En Francia se destacan, entre otros, Hubert ${ }^{15}$, Durkheim ${ }^{16}{ }_{17}$, Mialaret ${ }^{18}{ }^{19}$, Perrenaud $^{20}$, Meirieu $^{21}{ }^{22},{ }^{23}$ y Ranciére ${ }^{24}$. En España sobresalen los aportes de García ${ }^{25}$, Monereo $^{26}$, $\mathrm{Coll}^{27}$, Bisquerra $^{28}$, Traveset ${ }^{29}$, Colom, Bernabeu, Domínguez \& Sarramona $^{30}$ y Santos $^{31}$. La pedagogía anglosajona tiene entre sus principales

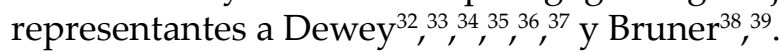

\footnotetext{
3 Juan Amos Comenio, Didáctica Magna (Madrid: Akal, 2012).

4 Juan Jacobo Rousseau, Emilio o de la Educación (Madrid: Alianza, 2011)

5 Juan Enrique Pestalozzi, Cómo Gertrudis enseña a sus hijos (México: Porrúa, 1801)

6 Johan Friedrich Herbart, Pedagogía General derivada del fin de la educación (Madrid: La Lectura, 1935)

7 Inmanuel Kant, Pedagogía (Madrid: Akal, 1803)

8 Paul Natorp, Curso de Pedagogía (Madrid: s/e, 1915)

9 Winthel Dilthey, "Ideas acerca de una psicología descriptiva y analítica", Obras completas, Vol. 6 (México: FCE, 1951)

10 Winthel Dilthey, Introducción a las ciencias del espíritu (Madrid: Alianza, 1980)

11 George Simmel, Pedagogía escolar, (Barcelona: Gedisa, 2008)

12 Niklas Luhmann, Teoría de la sociedad y pedagogía (Buenos Aires: Paidós, 1996).

13 Niklas Luhmann y Karl Eberhard Schorr "Presupuestos estructurales de una pedagogía reformista. Análisis sociológicos de la pedagogía moderna”, Revista Educación, No. 291 (1990): 55-79.

14 Niklas Luhmann y Karl Eberhard Schorr, El sistema educativo (problemas de reflexión) (México: Universidad de Guadalajara, 1993)

15 Rafael Hubert, Tratado de pedagogía general (París: s.e., 1965)

16 Emile Durkheim, Educación y sociología (Bogotá: Babel, 1976)

17 Emile Durkheim, La educación moral (Madrid: Trotta, 2002)

18 Gilbert Mialaret, Ciencias de la educación (Barcelona: Oikos-Tau, 1976)

19 Gilbert Mialaret, Introducción a las ciencias de la educación (Ginebra: UNESCO, 1985)

20 Phillie Perrenaud, Construir competencias desde la escuela (Santiago de Chile: Dolmen-Océano, 1999)

21 Pilippe Meirieu, Aprender, sí. Pero ¿cómo? (Barcelona: Octaedro, 1992)

22 Pilippe Meirieu, La opción de educar: Ética y Pedagogía (Barcelona: Octaedro, 2001)

23 Pilippe Meirieu, Carta a un joven profesor. Por qué enseñar hoy (Barcelona: Grao, 2005)

24 Jacques Ranciére, El maestro ignorante (Barcelona: Laertes, 1987)

25 Juan García, Teoría de la educación (Madrid: Anaya, 1984)

26 Carlos Monereo, Estrategias de enseñanza y aprendizaje (México: Fondo Mixto de Cooperación Técnica y Científica, 1988)

27 César Coll, Psicología y Currículum (Buenos Aires: Paidós, 1994)

28 Rafael Bisquerra, Modelos de la Orientación psicopedagógica (Barcelona: Boixareu Universitaria, 1998)

29 Miguel Traveset, La pedagogía sistémica. Fundamentos y práctica (Barcelona: Grao, 2007).

30 Antonio Colom Cañellas, Teorías e instituciones contemporáneas de la educación (Barcelona: Ariel, 2008)

31 Miguel Ángel Santos, La escuela que aprende (Madrid: Morata, 2000)

32 John Dewey, Democracia y educación. Una introducción a la filosofía de la educación (Madrid: Morata, 1916)

33 John Dewey, La escuela y el niño (Madrid: Ediciones de la Lectura, 1926)

34 John Dewey, La ciencia de la educación (Buenos Aires: Losada, 1964)

35 John Dewey, Cómo pensamos (Barcelona: Paidós, 1989)

36 John Dewey, Mi credo pedagógico (León: Universidad de León, 1997)

37 John Dewey, Experiencia y educación (Madrid: Biblioteca Nueva, 2003)

38 Jerome Bruner, La educación, puerta de la cultura (Madrid: Visor, 2000)

39 Jerome Bruner, La importancia de la educación (Barcelona: Paidós, 2012)
} 
En Latinoamérica son significativos los trabajos de Solari ${ }^{40}$, Lemus ${ }^{41}$, Luzuriaga $^{42}$, Prieto ${ }^{43}$, Saavedra \& Suárez ${ }^{44}$, Medina \& Salvador ${ }^{45}$, Hoyos et. al. $^{46}$, Civarolo $^{47}$, Díaz-Barriga ${ }^{48}$, Trejo ${ }^{49}$ y Mendoza $^{50}$. Asimismo, en el continente latinoamericano son relevantes los trabajos de autores cubanos y colombianos. En Cuba se destacan De la Torre ${ }^{51}$, Aguayo ${ }^{52}$, 53, González ${ }^{54}$, Álvarez de Zayas ${ }^{55}$, López $^{56}$, Álvarez de Zayas ${ }^{57}$, Fuentes \& Álvarez ${ }^{58}$, y Addine ${ }^{59}$, ${ }^{60}$. En Colombia resaltan Zuluaga ${ }^{61}, 62,{ }^{63}, 64,65,66,67,68$, De Zubiría ${ }^{69},{ }^{70}$, Zambrano ${ }^{71},{ }^{72},{ }^{73}$, De Zubiría \&

40 Manuel Solari, Pedagogía General (Buenos Aires: El Ateneo, 1966)

41 Luis Ángel Lemus, Pedagogía. Temas fundamentales (Buenos Aires: Kapeluz, 1969)

42 Luis Luzuriaga, Pedagogía (Buenos Aires: Lozada, 1984)

43 Blas Prieto, Principios generales de la educación (Caracas: Monte Ávila, 1985)

44 Raúl Saavedra y Miguel Suárez, Diccionario de pedagogía (México: Pax, 2001)

45 Ángel Medina y Francisco Salvador, Didáctica general (Madrid: Prentice-Hall, 2002)

46 Carlos Ángel Hoyos, Epistemología y objeto pedagógico ¿Es la pedagogía una ciencia? México: UNAM. Instituto de investigaciones sobre la Universidad y la Educación (IISUE), 2010.

47 María Mercedes Civarolo, La idea de la Didáctica (Bogotá: Magisterio, 2011)

48 Ángel Díaz-Barriga, Pensar la didáctica (Buenos Aires: Amorrortu, 2012)

49 Karina Trejo, Metodología del proceso enseñanza-aprendizaje (México: Trillas, 2012)

50 Carlos Mendoza, La pedagogía como ciencia: notas para un debate (Caracas: Universidad Pedagógica Experimental LibertadorUPEL, 2015)

51 Carlos De la Torre, Manual para los exámenes de maestros (La Habana: La Moderna Poesía, 1904)

52 Alfredo Aguayo, Pedagogía (La Habana: La Moderna Poesía, 1927)

53 Alfredo Aguayo, Filosofía y nuevas orientaciones de la educación (La Habana: Cultural, 1933)

54 David González, Introducción a la filosofía de la educación (La Habana: Cultural, 1946)

55 Carlos Álvarez de Zayas, La escuela en la vida (La Habana: Félix Varela, 1992).

56 Josefina López, El carácter científico de la pedagogía en Cuba (Ciudad de la Habana: Pueblo y Educación, 1996)

57 Rita Marina Álvarez de Zayas, Hacia un currículum integral y contextualizado (La Habana: Academia, 1997)

58 Homero Fuentes e Ilsa Álvarez, Dinámica del proceso docente educativo de la educación superior (Santiago de Cuba: CEES “Manuel F. Gran". Universidad de Oriente, 1998)

59 Fátima Addine, Didáctica y optimización del proceso de enseñanza-aprendizaje (La Habana: IPLAC, 1998)

60 Fátima Addine, Didáctica. Teoría y práctica (Ciudad de la Habana: Pueblo y Educación, 2004)

61 Olga Lucía Zuluaga, Hacia una historia de la práctica pedagógica colombiana en el siglo XIX (Medellín: Universidad de Antioquia, 1979)

62 Olga Lucía Zuluaga. Pedagogía e historia. La historicidad de la pedagogía. La enseñanza, un objeto de saber (Bogotá: Foro Nacional por Colombia, 1987)

63 Olga Lucía Zuluaga, “Educación y pedagogía”, Revista Educación y Cultura, Vol. 1, 1988: 11-26.

64 Olga Lucía Zuluaga, “El saber pedagógico: Experiencias y conceptualizaciones”, en Encuentros pedagógicos transculturales: Desarrollo comparado de las conceptualizaciones y experiencias pedagógicas en Colombia y Alemania, ed. José Antonio Echeverri (Medellín: Universidad de Antioquia, 1999), 81-88.

65 Olga Lucía Zuluaga, "El saber pedagógico: experiencias y conceptualizaciones", en Encuentros pedagógicos transculturales: desarrollo comparado de las conceptualizaciones y experiencias pedagógicas en Colombia y Alemania, ed. Centro Consolidado de Investigaciones Educativas y Pedagógicas, (Medellín: Editorial Marín Vieco, 2001), 81-88.

66 Olga Lucía Zuluaga, Pedagogía y Epistemología (Bogotá: Magisterio, 2003)

67 Olga Lucía Zuluaga, "El pasado presente de la pedagogía y la didáctica”. En Pedagogía y Epistemología, ed. Olga Lucía Zuluaga (Bogotá: Magisterio, 2003)

68 Olga Lucía Zuluaga. Foucault, la pedagogía y la educación. Pensar de otro modo (Bogotá: Magisterio, 2005)

69 Julián De Zubiría Samper, Los modelos pedagógicos (Bogotá: Fundación Alberto Merani, 1994)

70 Julián De Zubiría Samper, Los modelos pedagógicos. Hacia una pedagogía dialogante (Bogotá: Magisterio, 2011)

71 Armando Zambrano Leal, Pedagogía, educabilidad y formación de docentes (Cali: Nueva Biblioteca Pedagógica, 2001)

72 Armando Zambrano Leal, Didáctica, pedagogía y saber (Bogotá: Magisterio, 2005)

73 Armando Zambrano Leal, Los hilos de la palabra. Pedagogía y Didáctica (Bogotá: Magisterio, 2006) 
De Zubiría ${ }^{74}$, De Zubiría ${ }^{75},{ }^{76},{ }^{77}, 78,79$, Flórez $^{80}$, Quiceno ${ }^{81}{ }^{82}$ Tamayo $^{83}$, Runge ${ }^{84}$, ${ }^{85}$, Ríos $^{86}$, Martínez $^{87}$, Carvajal ${ }^{88}$, Bedoya ${ }^{89}$, Herrera $^{90}$, Hoyos $^{91}$, Echeverri ${ }^{92}$, Runge, Garcés \& Muñoz ${ }^{93}$ entre otros no menos importantes.

En Colombia encontramos además un nutrido número de autores que han estudiado las concepciones pedagógicas de otros países. Tal es el caso de Zambrano ${ }^{94}$, quien ha estudiado a profundidad la tradición pedagógica francesa, y Runge ${ }^{95}$, quien es experto en la pedagogía alemana. Son significativos también los aportes de Soto y Lafuente ${ }^{96}$ sobre la autonomía y modelos universitarios en América Latina, así como la concepción de Soto ${ }^{97}$ sobre la Universidad en el Periodo colonial, en el que se estudian las obras de educadores criollos neogranadinos. Por otro lado, Soto, Paniagua, Lima y Vera ${ }^{98}$ han hecho invaluables estudios sobre los educadores en América Latina y el Caribe de la Colonia al siglo XIX-XX.

74 Miguel De Zubiría Samper y Julián De Zubiría Samper, Fundamentos de Pedagogía Conceptual (Bogotá: Plaza y Janés, 2002)

75 Miguel De Zubiría Samper, Pedagogía Conceptual. Desarrollos filosóficos, pedagógicos y psicológicos (Bogotá: Fundación Internacional de Pedagogía Conceptual, 2004)

76 Miguel De Zubiría Samper, Pedagogías del siglo XXI: Mentefactos I. El arte de pensar para enseñar y de enseñar para pensar (Bogotá: Fundación Internacional de Pedagogía Conceptual, 2006)

77 Miguel De Zubiría Samper, Los fines y el método de la Pedagogía Conceptual (Bogotá: Fundación Internacional de Pedagogía Conceptual, 2008a)

78 Miguel De Zubiría Samper, Formar, no solo educar (Bogotá: Fundación Internacional de Pedagogía Conceptual, 2008b)

79 Miguel De Zubiría Samper, Las teorías de Pedagogía Conceptual (Bogotá: Fundación Internacional de Pedagogía conceptual, 2008c)

80 Rafael Flórez Ochoa, Pedagogía del conocimiento (Bogotá: McGraw-Hill, 1994)

81 Humberto Quinceno, "Michel Foucault, ¿pedagogo?", en Foucault, la Pedagogía y la Educación. Pensar de otro modo, ed. Olga Lucía Zuluaga (Bogotá: Magisterio, 2005)

82 Humberto Quinceno, "Sujeto y subjetividad en las ciencias de la educación en Colombia. El docente, el profesional y el intelectual", en Paradigmas y conceptos en educación y pedagogía, José Antonio Echeverri (Bogotá: Siglo del Hombre, 2015)

83 Luis Antonio Tamayo, “Tendencias de la pedagogía en Colombia”, Revista Latinoamericana de Estudios Educativos, Vol. 3 (1), enerojunio, 2007: 65-76.

84 Andrés Klaus Runge, Ensayos sobre Pedagogía Alemana (Bogotá: Universidad Pedagógica Nacional, 2008)

85 Andrés Klaus Runge, “Una epistemología histórica de la pedagogía: El trabajo de Olga Lucía Zuluaga”, Revista de Pedagogía, Escuela de Educación, Universidad Central de Venezuela, 2015.

86 Raúl Ríos. Las ciencias de la educación en Colombia. 1926-1954 (Bogotá: Magisterio, 2008)

87 Ángel Martínez, "Figuras contemporáneas del maestro en América Latina”, en Treinta años del Grupo Historia de la Práctica Pedagógica, eds. Antonio Álvarez y Ángel Martínez (Bogotá: Magisterio, 2010)

88 Gilberto Carvajal, "La lógica del concepto de pedagogía”, Revista Iberoamericana de Educación, OEI, 2010.

89 José Iván Bedoya, Epistemología y Pedagogía. Ensayo histórico sobre el objeto y método pedagógicos (Bogotá: ECOE, 2013)

90 José Darío Herrera, Pensar la educación, hacer investigación (Bogotá: Universidad de la Salle, 2013)

91 Gilberto Hoyos, Filosofía de la Educación. Apuntes de su último seminario de doctorado (Bogotá: Siglo del Hombre, 2013)

92 José Antonio Echeverri, Paradigmas y conceptos en educación y pedagogía (Bogotá: Siglo del Hombre, 2015)

93 Andrés Klaus Runge, Juan Fernando Garcés y David Antonio Muñoz, "La pedagogía como campo profesional y disciplinar. Lugar estratégico para enfrentar las tensiones entre el reconocimiento científico, la profesionalidad y la regulación socio-estatal de la profesión docente", en Paradigmas y conceptos en educación y pedagogía, ed. José Antonio Echeverri (Bogotá: Siglo del Hombre, 2015)

94 op. cit.

95 op. cit.

96 Diana Soto Arango y María Isabel Lafuente Guantes, Autonomía y modelos universitarios en América Latina y España (Tunja: Universidad de León-Búhos Editores, 2007)

97 Diana Soto Arango, La Universidad en el Periodo colonial. Educadores criollos neogranadinos (Tunja: Ediciones Doce Calles, 2011)

98 Diana Soto Arango et. al. Educadores en América Latina y el Caribe de la Colonia al siglo XIX-XX (Tunja: Ediciones Doce Calles, 2011) 
Ahora bien, es preciso poner a dialogar a los autores de los diversos países sobre el estatuto epistemológico de la pedagogía. Es interesante escuchar no solo a los pedagogos de la postmodernidad sino tener en cuenta además los aportes de autores latinoamericanos que desarrollaron su obra a inicios y mediados del siglo XIX, como De la Torre ${ }^{99}$, Aguayo ${ }^{100}$, González ${ }^{101}$, Solari ${ }^{102} y_{\text {Lemus }}{ }^{103}$, junto a otros autores europeos como Hubert ${ }^{104}$.

El análisis de las diferentes concepciones de la Pedagogía se convierte así en el problema científico que se aborda en este artículo, cuyos objetivos claves son precisamente hacer una revisión temática reflexiva que permite analizar la génesis, evolución y configuración epistémica de la pedagogía, así como identificar y valorar las principales tendencias que han proliferado en la historia de la educación y sus orientaciones epistemológicas. Este artículo se fundamenta en una investigación bibliográfica y de corte documental, soportado en el método de análisis de fuentes y especialmente una visión comparada de las concepciones sobre pedagogía que se han configurado en los diversos países abordados.

Los seres humanos que han configurado culturalmente la pedagogía (investigadores sociales, filósofos, pensadores, profesores y maestros) tienen en común un sistema de referentes comunes, algo similar a lo que Bourdieu ${ }^{105}$ evocaba con el nombre de campo de las posibilidades estratégicas. Pero Foucault ${ }^{106}$ afirma la autonomía absoluta de ese campo al que llama episteme y rechaza como ilusión doxológica el intento de encontrar el principio explicativo de lo que sucede en dicho campo en las divergencias de intereses o de hábitos mentales en los individuos y en el campo de la polémica, ambos definidos por Bourdieu. Es decir, Foucault transfiere al cielo de las ideas las oposiciones y los antagonismos que hunden sus raíces en las relaciones entre los productores y los usuarios de las obras, en este caso pedagógicas.

Por otro lado, según Zambrano ${ }^{107}$ desde la filosofía, el concepto se asocia a una región de saber con el potencial de visibilizar los componentes traídos a la realidad. Estos componentes definen el concepto. "Todo concepto tiene componentes y se define por ellos"108. Por ejemplo, el concepto de pedagogía incluye la formación, pero también el proceso o el hecho educativo, la escuela, la disciplina, el sistema, el poder, el sujeto, la enseñanza y el aprendizaje. "Por sus componentes, el concepto tiene una historia, lo cual no implica que sea primero que otro. La posición en el pensamiento responde a su capacidad de explicación,

\footnotetext{
99 op. cit.

100 op. cit.

101 op. cit.

102 op. cit.

103 op. cit.

104 op. cit.

105 Pierre Bourdieu, Razones prácticas. Sobre la teoría de la acción (Barcelona: Anagrama, 2007)

106 Michel Foucault, Las palabras y las cosas. Una arqueología de las ciencias humanas (México: Siglo XXI, 1966)

107 op. cit. 2005.

108 Gilles Deleuze, Qué es la filosofía (Barcelona: Anagrama, 1999), 21.
} 
a la manera como sus componentes permiten situarnos en el mundo"109. La disposición de los componentes del concepto hace que este sea diferente con relación a otros conceptos. "Ellos remiten refractar y explicar la realidad. En la primera condición, el concepto sirve de terreno para una visión del mundo o una parte de este. En la segunda, su función es explicar, crear una discursividad que como fuerza articula, repite y crea intersecciones" ${ }^{110}$.

Todo concepto es histórico, oscilántico, dinámico, cíclico y dialéctico, se configura en forma de zigzag, al estilo del vuelo de las mariposas, dialogando con sus propias tensiones, paradojas y contradicciones. De ahí que en un concepto "siempre hay porciones o trozos de componentes de otros conceptos que respondían a otros o suponían otros planos"111.

Pedagogía, ante todo, es un concepto. No hay ciencia sin configuración lingüística. No hay saber pedagógico sin discurso. No hay reflexión sin lenguaje. No hay enseñanza sin palabras, sin nociones y sin conceptos. Los seres humanos somos los únicos seres vivos que no podemos vivir sin conceptos. Nuestra vida es una configuración conceptual comprensiva. Los conceptos definen nuestra configuración vital.

A lo largo de la historia y el desarrollo de la humanidad y de las Ciencias de Educación han proliferado diversas percepciones sobre el estatuto epistemológico y el carácter científico de la Pedagogía. Estas percepciones, imaginarios y criterios difieren según los países, la época, las prácticas pedagógicas y los autores. Algunos consideran que es una ciencia, otros consideran que es un arte, otros la asocian a la filosofía y algunos esbozan un enfoque integrador.

En el caso concreto de Latinoamérica, varios autores han configurado el objeto de estudio de la pedagogía y han asumido sus postulados como ciencia, a partir de una asimilación acrítica y dogmática de los presupuestos de la exURSS y la antigua República Democrática Alemana, sin armonizarlos con la amplia y diversa experiencia pedagógica Latinoamericana ni con las condiciones históricas y socioculturales de cada país. Es evidente la necesidad de profundizar en el estudio de la configuración epistémica de la noción de pedagogía con el fin de intensificar nuevamente y exaltar el debate conducente a develar su estatuto epistemológico y establecer sus bases teóricas, contribuyendo de esta manera al mejoramiento y transformación de la práctica pedagógica.

Runge, Garcés y Muñoz ${ }^{112}$ señalan que en Colombia proliferan diferentes concepciones sobre pedagogía. Para cada actividad humana existe una respectiva pedagogía. No solo los académicos utilizan la expresión "pedagogía" para referirse a cuestiones diferentes, sino que en casi todas las profesiones y actos se utiliza una pedagogía específica. De esta manera, los agentes de tránsito colocan comparendos pedagógicos, se habla de pedagogía de la pregunta, pedagogía del cuerpo, pedagogía del texto, pedagogía de la ternura, la caricia o el amor;

\footnotetext{
109 op. cit., p. 44.

110 Ídem.

111 Gilles Deleuze, óp. cit., p. 21.

112 op. cit.
} 
la policía en los colegios habla de la pedagogía de la requisa, y en las zonas de conflicto se intenta desarrollar una pedagogía de la tolerancia.

A partir de lo anterior, en este trabajo de revisión temática reflexiva se hace un análisis sobre la génesis, evolución y configuración epistémica de la noción de pedagogía, identificando cinco tendencias u orientaciones epistemológicas: la pedagogía como ciencia de la educación, la pedagogía como una de las ciencias de la educación, la pedagogía como saber pedagógico, la pedagogía como arte de enseñar (didáctica) y la pedagogía como reflexión sobre la educación. A continuación se desarrollan cada uno de estos tópicos.

\section{Génesis y evolución de la noción de pedagogía}

En la antigua Grecia se denominaba pedagogía a la actividad desarrollada por los esclavos para guiar y cuidar a los niños, vigilarlos, llevarlos, traerlos y estimular la memorización de alguna información. Un pedagogo era el esclavo encargado de guiar a los niños. Esta era una actividad subvalorada. La pedagogía era una actividad eminentemente doméstica. La palabra pedagogía deriva del griego (Paidós, niño; agogía, conducción) ${ }^{113}$. Es preciso destacar que el uso moderno de la noción de pedagogía difiere del sentido dado en la antigua Grecia, que consideraba al pedagogo como el esclavo que acompañaba al niño al sitio donde se educaba, cuidándolo y vigilándolo en el camino.

Martínez ${ }^{114}$ piensa y estudia la educación sin necesidad de pensar la pedagogía, pero esta no puede pensarse sin la educación. Aunque desde el punto de vista conceptual y etimológico, la Pedagogía es la ciencia, disciplina o teoría encargada de estudiar la educación y formación de los niños y niñas, esta abarca el conocimiento regulador del proceso educativo y ha servido como base para el estudio integral de la educación en cualquier edad. Se extiende el concepto a todos los niveles educativos y etapas etarias. De esta manera, el término pedagogía se aplica también a la educación de adolescentes, jóvenes y adultos, no solo a la educación infantil. Sin embargo, algunos autores ${ }^{115}$ consideran que la ciencia que estudia la formación del ser humano es la Antropogogía, y que esta debería subdividirse por cada una de las etapas etarias: niñez, adolescencia y juventud, adultez y adulto mayor. De esta manera, tendríamos diversas disciplinas respectivamente: pedagogía, hebegogía, andragogía y gerentogogía.

Herbart ${ }^{116}$ subestimó y soslayó en los postulados de su pedagogía sustentada en la psicología el papel del cerebro como soporte material y de la conciencia como principio cognitivo de los fenómenos psíquicos. "Quizá sería mejor que la pedagogía intentara, en cuanto le fuese posible, deliberar sobre sus propios conceptos y cultivar más una reflexión independiente; de esta manera llegaría

113 Solari, op. cit.

114 op. cit.

115 Carlos Carreras, Aprender a formar. Educación y procesos formativos (Barcelona: Paidós, 2003)

116 op. cit., p. 8. 
a ser el centro de un círculo de investigaciones y no correría el peligro de ser gobernada por un extranjero como lejana provincia conquistada".

A principios del siglo XIX, cuando surge la pedagogía en la obra de Herbart, esta noción era utilizada para referirse a hechos relacionados con la educación. La Pedagogía era considerada un saber teórico específico de contenido educativo. Era una disciplina cuyo objeto de estudio era todo lo educativo. Incluso Herbart hablaba de pedagogía general. Pero siempre existió el temor de que fuese absorbida por otros discursos también educativos y no lograra configurar su identidad.

A lo largo del devenir socio-histórico de la educación han proliferado diversas concepciones que han problematizado sobre el carácter científico de la Pedagogía y han debatido si es un arte, una técnica, una ciencia e incluso, una filosofía. Algunos autores la consideran la ciencia de la educación, otros la ubican dentro del amplio espectro de las ciencias de la educación, como una más entre ellas, otros consideran que es una disciplina científica pero que aún no alcanza el rango de ciencia, otros la asocian a la Didáctica, entendiendo que se preocupa por el acto de enseñar, y algunos la analizan solo como la reflexión sobre la educación.

Para Lemus ${ }^{117}$ el objeto de estudio de la pedagogía es el planteamiento, investigación y solución del problema educativo. La asocia al conjunto de leyes, principios y normas que regulan el hecho educativo. En cambio Luzuriaga ${ }^{118}$ considera que la pedagogía integra las diversas exégesis existentes sobre la educación: como arte, como técnica, como teoría, como ciencia y como filosofía.

Por otro lado, para Titone ${ }^{119}$ la pedagogía es el conjunto de conocimientos sistemáticos relacionados con el fenómeno educativo, y Prieto ${ }^{120}$ sostiene que la pedagogía estudia la educación desde la unidad comprensiva entre el agente educador y el sujeto de la educación, estableciendo las finalidades que orientan el acto educativo y fijando los principios formativos.

De esta manera, la pedagogía estudia los contenidos teóricos y prácticos de la educación, regula la práctica del proceso educativo y estudia la teoría del mismo ${ }^{121}$. De ahí que sea considerada la disciplina y teoría comprensiva y explicativa de la educación, que intenta su constante mejoramiento y "transformación ética y axiológica de las instituciones formativas y de la realización integral de todas las personas" 122

Como se aprecia, cualquiera que sea la concepción que se tenga de la educación: fenómeno, hecho o proceso, la teoría que la estudia es denominada pedagogía. Es decir, la pedagogía, sea considerada ciencia, arte, tecnología o

\footnotetext{
117 op. cit.

118 op. cit.

119 Raúl Titone, Metodología Didáctica (Buenos Aires: Rialp, 1985)

120 op. cit.

121 Raúl Saavedra y Miguel Suárez, op. cit.

122 Ángel Medina y Francisco Salvador, op. cit., p. 31.
} 
filosofía, estudia el fenómeno, hecho o proceso educativo. La pedagogía es la teoría que estudia, se preocupa y se ocupa de la educación como praxiología.

Runge utiliza la expresión pedagogía como categoría general para designar un campo disciplinar de estudio e investigación que se institucionalizó y academizó durante el siglo XVIII, a través de la primera cátedra de pedagogía, creada en 1779 en la Universidad de Halle, para lo cual se nombró al pedagogo Ernst Christian Trapp, quien "luchó por darle una autonomía a la pedagogía, oponiéndose a las injerencias políticas y religiosas sobre la educación, y planteó, además, que dicha disciplina tuviera un sustento científico (empírico-experimental)" ${ }^{123}$. En la tradición alemana la pedagogía es reconocida como parte de las ciencias sociales y humanas.

La pedagogía debe "sentar las bases para su localización dentro de la taxonomía de las ciencias, especificar su método o métodos de investigación, delimitar en qué medida afecta a su propia identidad el hecho de que su objeto de trabajo sea la educación"124. A partir de estas conceptualizaciones, la pedagogía puede analizarse como ciencia de la educación, pero debe demostrar que realmente lo es.

\section{La pedagogía como ciencia de la educación}

En la segunda mitad del siglo XVII, el teólogo y filósofo checo Juan Amos Comenio intenta ascender a la pedagogía a la cúspide científica, la moderniza y la considera como una ciencia, desde una mirada incipiente de lo que era la ciencia en los años 1600, que estaba referida a toda disciplina que tuviese un objeto de estudio y un método para abordar dicho objeto, que se declara como la formación del niño. Desde esta época comienza a valorarse la pedagogía como una disciplina encaminada a la formación de los seres humanos, a partir de la visión específica que se tenga de ser humano y de sociedad.

Comenio desarrolló su sistema pedagógico en el siglo XVII, sin embargo el ser humano tuvo que esperar 200 años para que en el siglo XIX la pedagogía lograra "reflexionar sobre sus conceptos autóctonos y cultivar más un pensar autónomo" 125 .

Herbart señalaba que la pedagogía debe volver "con la mayor precisión posible a sus conceptos autónomos y cultive un pensar autóctono, de modo que se constituya en centro de un círculo de investigación"126. De ahí que cualquier reflexión epistémica sobre el estatuto científico de la pedagogía debe tener en cuenta esta advertencia. Es preciso estudiar la pedagogía como una disciplina que intenta configurarse y erigirse en ciencia a la vez que trata de captar o aprehender el complejo fenómeno de la educación ${ }^{127}$.

\footnotetext{
123 op. cit., p. 30.

124 Juan García, op. cit., p. 11.

125 Johan Friedrich Herbart, op. cit., p. 28.

126 Ídem, p. 35.

127 José Iván Bedoya, op. cit.
} 
Es sabido que las obras de Rousseau y Pestalozzi pueden ser consideradas la génesis fecunda y el germen de la pedagogía científica, por cuanto abordaron valiosas ideas sobre la educación, pero fue Herbart quien maduró y edificó el sistema científico de la pedagogía. Su obra clásica Pedagogía General derivada de los fines de la educación, es el primer ensayo magistral que intenta reorientar la actividad educativa espontánea hacia un sistema científico. Nadie antes que Herbart propone una configuración armónica y coherente establecida con un amplio rigor científico. Nadie antes que Herbart configura una ciencia de la educación: la pedagogía.

Pero la pedagogía es ciencia para Herbart porque sustenta su configuración epistémica en dos ciencias filosóficas: la ética y la psicología. De esta manera, la ética tiene una dimensión teleológica en tanto que determina el fin de la educación, y la psicología tiene una dimensión procesual por cuanto regula los medios que permiten alcanzar el fin. Es por ello que para Herbart todo maestro pedagogo es también filósofo. "La pedagogía como ciencia es asunto de la filosofía, pero de toda la filosofía, tanto de la teórica como de la práctica, y tanto también de la más profunda investigación transcendental como del razonamiento que recoge superficialmente toda clase de hechos"128

Ahora bien, según Runge, para fundamentar el carácter científico de la pedagogía, Herbart tuvo que plantear en 1802, en su "Primera Lección sobre Pedagogía", la necesidad de diferenciar la pedagogía como ciencia, del arte de la educación. En este sentido señala:

Diferencien ante todo la pedagogía como ciencia del arte de la educación. ¿Cuál es el contenido de una ciencia? Un conjunto organizado de proposiciones que constituyen una totalidad de pensamientos [...] ¿Qué es un arte? Una suma de destrezas que se tienen que unir para producir un fin. La ciencia exige entonces la derivación de proposiciones a partir de sus principios, es decir, pensamiento filosófico; el arte exige un obrar permanente de conformidad con los resultados de aquél [...] Diferencien además el arte del educador instruido del ejercicio particular de ese arte. ${ }^{129}$

La mayoría de los autores coinciden en afirmar que Herbart es el fundador de la pedagogía como ciencia, sustentada en la psicología, entendiendo que ningún autor antes que él fue capaz de proponer un sistema riguroso y científico, tomando en serio la inmensa tarea de configurar una ciencia de la educación. Fue Herbart quien propuso el término pedagogía para sistematizarla como ciencia de la educación.

Dewey ${ }^{130}$ también dedicó múltiples trabajos al problema de la pedagogía como ciencia y su relación con la filosofía. Como ya se ha expresado, esta problemática había sido planteada inicialmente por Herbart, quien afirmó que

128 Johan Friedrich Herbart, op. cit., p. 266.

129 Herbart, 1986, p. 55, citado en Runge, op. cit., p. 54.

130 op. cit. 
"la pedagogía como ciencia es asunto de la filosofía"131. El tema volvió a ser tratado en 1884 por Dilthey ${ }^{132}$, quien negó el carácter de validez general de esta, solo asignado al racionalismo. Dewey consideraba que "la flor y el fin de toda verdadera filosofía es la pedagogía, en su más amplio sentido, como teoría de la formación del hombre"133

Muchos autores han considerado a la pedagogía como una ciencia sociohumana o del espíritu, la ubican a la misma altura que la Psicología o la Sociología. Sin embargo, Dewey adopta una posición peculiar pragmatista para abordar el problema del carácter científico de la pedagogía, ubicándola como medio de la acción educativa. No niega su carácter científico, pero le asigna una dimensión procedimental, orientada y sustentada en la experiencia. De hecho, comparaba a la pedagogía con la medicina, argumentando que el educador actúa de manera mecánica como el médico, quien subordina el caso individual a la clasificación general. Decía que el médico pragmático es un artista que usa su ciencia para diseñar y aplicar instrumentos que le permitan comprender el caso particular. Asimismo, no existen dos niños iguales porque en cada individuo hay algo inconmensurable.

Por otro lado, González precisó que el objeto de estudio de la pedagogía es la educación del niño o del joven y "esta es la única ciencia que se ocupa de ello (...) aunque algunos de sus aspectos sean tratados por otras ciencias, estas carecían de unidad para los fines que la educación persigue"134

Asimismo, Simmel reconoce el carácter científico de la pedagogía, pero para él es más un arte que una ciencia. Afirma que todos los seres humanos somos pedagogos pre-existenciales, por cuanto la pedagogía es parte existencial de la vida, algunos la cultivan más y otros menos.

En el semestre del invierno de 1915/1916, hacia el final de su vida, George Simmel dictó en la Universidad de Estrasburgo algunas lecciones sobre pedagogía, bajo el título de Pedagogía escolar, que aparecieron publicadas después de su muerte en 1922. "La pedagogía es una ciencia y técnica dualista: a través de que sus exigencias tienen siempre, a la vez, un contenido subjetivo y uno objetivo, ella está continuamente obligada a mixturas, compromisos y fusiones de intereses. En fin, nosotros recorremos el camino más unificado, siempre, con dos piernas" 135

Con relación a la cientificidad de la pedagogía, Luzuriaga considera que es una ciencia debido a que "cuenta con un objeto de estudio propio, que es la educación; con métodos para resolver sus problemas, como la observación, la experimentación, comprensión e interpretación; asimismo, dispone de unidad y sistema para organizar el resultado de sus estudios" ${ }^{136}$. Prieto también señala

\footnotetext{
131 Johan Friedrich Herbart, op. cit., p. 40.

132 op. cit.

133 op. cit., 1964, p. 45.

134 op. cit., p. 108.

135 op. cit., p. 32.

136 op. cit., p. 20.
} 
que el objeto de estudio de la pedagogía no es inherente a otras ciencias, tiene uno o varios métodos para estudiar su objeto y "ha llegado a organizar el resultado de sus investigaciones para construir un sistema unitario de leyes y principios de carácter general"137.

La mayoría de los autores latinoamericanos coinciden en que el proceso socio-histórico del desarrollo de la pedagogía como ciencia transita por diferentes etapas. "La pedagogía como ciencia surge después de un largo proceso de desarrollo, pasando de experiencias cotidianas, de opiniones aisladas acerca de la educación a acabados sistemas pedagógicos" 138 .

Habermas ${ }^{139}$ afirma que toda ciencia social que se respete, incluyendo a la pedagogía, tiene tres componentes: histórico, teórico y metodológico. La pedagogía tiene las condiciones para ser considerada una verdadera ciencia independiente por cuanto, además de haber configurado teorías para resolver los problemas educativos, posee un sistema para lograrlo ${ }^{140}$. No obstante, Kenneth propone no considerar a la pedagogía como la Ciencia de la Educación por cuanto ciencia se refiere a logro, no solo a deseo, y aún no existe "una masa suficientemente organizada de leyes y hechos educativos para garantizar el término" ${ }^{141}$. Sin embargo, la mayoría de los autores cubanos a lo largo de la historia de la educación han mostrado una concepción de una pedagogía científica experimental ${ }^{142}$. Las bases paidológicas de esta pedagogía fueron propugnadas por destacados pedagogos a inicios del siglo XX, como por ejemplo Aguayo ${ }^{143}$. En cambio, en Colombia, los debates sobre el carácter científico de la pedagogía se convirtieron en un obstáculo epistemológico para el conocimiento profundo y el análisis de la esencia y naturaleza del saber pedagógico ${ }^{144}$

Como se aprecia, desde la mirada de estos autores, la pedagogía se reconoce como la ciencia de la educación (en singular), la única. La pedagogía desde esta contemplación no reconoce otras ciencias de la educación, y sustenta su legitimidad a partir de infinitos argumentos tomados tanto de las ciencias sociales y humanas como de las ciencias naturales. Sin embargo, otros autores, aun considerándola una ciencia, afirman que no es la única ciencia de la educación, señalan que la educación como fenómeno complejo se estudia por múltiples ciencias, y en este sentido ubican a la pedagogía al mismo nivel que la constelación de las ciencias de la educación.

\footnotetext{
137 op. cit., p. 34 .

138 op. cit., p. 34.

139 Jürgen Habermas, Teoría de la acción comunicativa (Madrid: Trotta, 2010)

140 Karina Trejo. óp. cit.

141 Rafael Kenneth, La revolución de la enseñanza (La Habana: Edición Revolucionaria, 1975), 99.

142 Josefina López, óp. cit.

143 op. cit.

144 Andrés Klaus Runge, óp. cit., 2015.
} 


\section{La pedagogía como una de las ciencias de la educación}

Díaz ${ }^{145}$ señala que la pedagogía fue estremecida por dos acontecimientos de su historia reciente: a finales del siglo XIX, el surgimiento y desarrollo de las ciencias de la educación, y a finales del siglo XX, la crisis de la pedagogía científica a partir de la emergencia de la etapa postmodernista.

La mayoría de las ciencias humanas en su esplendoroso desarrollo comienzan a estudiar la educación. De esta manera, la antropología, la filosofía, la psicología, la sociología, y por último la economía, fertilizaron, complementaron y enriquecieron la configuración epistémica de la educación. Esta penetración epistémica del hecho educativo se amplió a diversas ciencias como la biología, derecho, ecología, medicina, psiquiatría, y más recientemente las neurociencias, las cuales de una $\mathrm{u}$ otra forma han estudiado el fenómeno educativo.

Para referirse al concepto Pedagogía, muchos autores en ocasiones emplean el término ciencia de la educación, en singular. Otras veces se refieren a las ciencias de la educación, en plural. Incluso se habla del sistema de las ciencias pedagógicas. Labarrere \& Valdivia ${ }^{146}$ y Álvarez ${ }^{147}$ señalan que la pedagogía es la ciencia de la educación, pero sin justificar por qué utilizan esta denominación y no las otras. Esto revela un limitado análisis teórico sobre esta problemática epistemológica de la pedagogía, que define su estatuto epistémico.

Por otro lado, algunos autores utilizan la expresión pedagogía con un significado similar al de ciencia de la educación o de ciencias de la educación, en dependencia de las tradiciones científicas que utilizan esta polémica noción. Runge $^{148}$ refiere que la expresión ciencia de la educación apareció en 1812 en una obra de Marc-Antonie Jullien de París (1778-1848), fundador de la pedagogía comparada. En el discurso pedagógico Latinoamericano se piensa que esta noción es más contemporánea, y no se sospecha que emergió apenas seis años después de haber sido publicada la obra clásica de Herbart en la que propone la noción de pedagogía. En el caso de Colombia, las ciencias de la educación emergen desde el año $1926^{149}$.

Kant ${ }^{150}$ no hablaba de ciencia de la educación sino de pedagogía, pero para él la pedagogía era la ciencia de la educación, la cual se representa su objeto, es decir, la educación, a través de la intuición y de la imaginación. En cambio, en la tradición francesa, a partir de la obra de Durkheim, se estableció una diferencia bien marcada entre pedagogía (aproximación teórica, práctica, prescriptiva y orientadora de la educación) y ciencias de la educación (aproximación descriptiva, científica y disciplinar de la educación).

145 Mario Díaz, "Pedagogía, discurso y poder", en Pedagogía, discurso y poder, eds. Mario Díaz y Javier Muñoz (Bogotá: Corprodic, 1990), 39-67.

146 Guillermina Labarrere y Gladys Valdivia, Pedagogía (La Habana: Pueblo y Educación, 1988).

147 Carlos Álvarez de Zayas, op. cit.

148 Andrés Klaus Runge, op. cit., 2008.

149 Raúl Ríos, op. cit.

150 op. cit. 
Si bien es cierto que Durkheim ${ }^{151}$ no se refería a las ciencias de la educación en plural, considera que las intuiciones e imaginaciones son múltiples, y por tanto la educación debe representarse como un objeto múltiple, mediante las ciencias de la educación, excluyendo de esta manera a la pedagogía y usurpando su lugar para estudiar su objeto: la educación. De esta manera podemos establecer diferencias sustanciales entre la pedagogía, la ciencia de la educación y las ciencias de la educación. Para Durkheim, la pedagogía es "la reflexión, lo más metódica y mejor documentada posible, puesta al servicio de la práctica de la enseñanza"152.

Mialaret ${ }^{153}$ conceptualiza a las ciencias de la educación como el conjunto de las disciplinas que estudian los hechos y situaciones educativas en su contexto socio-histórico. Afirma que estas ciencias tienen en común a la educación como objeto de estudio. Incluye dentro de las ciencias de la educación a la demografía escolar, economía de la educación, etnología, filosofía de la educación, fraseología de la educación, historia de la educación, planificación de la educación, psicología de la educación y sociología de la educación. No utiliza la noción de pedagogía y en sustitución de esta usa el término ciencias pedagógicas, como aquella parte de las ciencias de la educación especializadas en estudiar el funcionamiento y dinámica de las situaciones educativas cotidianas. Para este autor las ciencias pedagógicas son disciplinas científicas, abarcan las ciencias de la comunicación, ciencias de la evaluación, didácticas, métodos, técnicas y teoría de los programas. En efecto, en la actualidad el saber pedagógico es propiedad y patrimonio de las ciencias de la educación como configuración de disciplinas múltiples estudiosas del fenómeno educativo, objeto que solo era estudiado de manera individual por la pedagogía. Las denominadas ciencias de la educación estudian el mismo objeto que la pedagogía: la educación. Esta proliferación de ciencias que estudian lo educativo ha traído como consecuencia el abordaje pluriepistemológico y multimetódico consecuencia de la configuración de enfoques, métodos y procedimientos propios de las diversas ciencias humanas y sociales que conformaron las ciencias de la educación, sin que la pedagogía perdiera su identidad.

Runge, Garcés y Muñoz ${ }^{154}$ utilizan la noción de pedagogía para designar el campo profesional y que se ocupa de la educación en sus múltiples formas y dimensiones. En este sentido, el concepto de pedagogía es comparable con el de ciencias de la educación, surgido en Francia, el de ciencia educativa en la concepción anglosajona y el de ciencia de la educación en la tradición alemana. En cada país este proceso ha tenido sus particularidades distintivas. En Francia, en Alemania, en Estados Unidos, en Cuba y en el resto de Latinoamérica el debate con relación a las nociones de pedagogía, ciencias de la educación ha tenido ribetes específicos y diferentes entre sí. En el caso particular de Colombia la emergencia de la pedagogía como ciencia de la educación "fue aceptada

\footnotetext{
151 op. cit.

152 op. cit., 2002, p. 66.

153 op. cit., 1985.

154 op. cit.
} 
y acogida, debatida y rechazada, es decir, problematizada"155. El estatuto epistemológico de la pedagogía sufrió una extraordinaria metamorfosis. No es lo mismo el estado epistémico de la pedagogía como ciencia de la educación, a su situación como miembro de la amplia constelación de las ciencias de la educación.

En este estado, la pedagogía dialoga con las ciencias de la educación, interactúa con ellas y se reconoce como una de ellas, las guía y se nutre de ellas, impacta y es impactada teóricamente. Ocupa un lugar central y privilegiado en las ciencias de la educación por cuanto cuestiona, interroga, indaga y problematiza de manera original, sui generis, diferente y creativa, sobre el quehacer de las demás ciencias de la educación. En este sentido ha alcanzado una fuerte autonomía al interior del paradigma de las ciencias de educación ${ }^{156}$. Una perspectiva diferente nos muestra Runge ${ }^{157}$, quien señala que cuando la pedagogía estudiaba sus objetos guiada por las ciencias de la educación, fragmentaba dichos objetos, los mostraba incompletos, y ella misma emergía diluida y casi sin especificidad como saber crítico y fundante dentro de la educación.

No obstante, muchos autores reconocen y valoran la relación entre la pedagogía con otras ciencias, principalmente la sociología, la biología, la psicología, y sobre todo la filosofía. De la Torre ${ }^{158}$ señala las estrechas relaciones de la pedagogía con la fisiología y la psicología, cuyo objeto de estudio es el ser humano desde una dimensión física y mental. Señala además sus íntimas relaciones con la sociología, sobre todo en lo relacionado con la ética y la moral. Y finalmente, puntualiza que la pedagogía se relaciona con la lógica y con la higiene escolar.

Aguayo $^{159}$ le asigna una alta importancia a la relación de la pedagogía con la sociología y la psicología, por cuanto consideraba la pedagogía general como la constelación más abarcadora en la que se insertan varias disciplinas, entre las cuales incluyó a la sociología pedagógica y la psicopedagogía. González señalaba que la pedagogía tiene un sustrato filosófico que la orienta científicamente, "es una teoría que lleva latente una filosofía. Es inconcebible una pedagogía sin una filosofía del hombre. Cuando la pedagogía se desvele, la filosofía cae en una técnica rutinaria" ${ }^{\prime 160}$.

Por otro lado, Hubert concibe a la pedagogía como un conjunto holístico integrado por varias disciplinas, la relaciona con un edificio de varios pisos de los cuales "uno pertenece a la ciencia, el otro a la moral o a la filosofía práctica, el tercero a las técnicas y el último a la creación estética"161. Desde esta mirada integradora no es posible hacer una calificación reduccionista de la pedagogía, por cuanto es todo a la vez: técnica y arte, ciencia y reflexión práctica. Asimismo, Mattos postulaba una pedagogía que además de ciencia es técnica y filosofía

\footnotetext{
155 op. cit., 2015, p. 123.

156 Armando Zambrano, op. cit., 2001.

157 Andrés Klaus Runge, op. cit., 2015.

158 op. cit.

159 op. cit., 1927.

160 David González, op. cit., p. 22.

161 op. cit., p. 101.
} 
de la educación, lo cual permite superar "definiciones restrictivas unilaterales y confusas, según las cuales la pedagogía es el arte de educar, ya la ciencia de la educación, ya la ciencia y la técnica de la educación"162.

Es notable la ausencia de un diálogo respetuoso entre las diversas ciencias de la educación que contribuya a "legitimar el progreso de estas ciencias hacia la pedagogía para que ella no perezca como una técnica porque, desde la postura de las ciencias de la educación, la pedagogía cada vez más se hundirá en el más crudo tecnicismo"163. Para evitarlo, debe configurar su propio sendero y autoconfigurarse como un sólido saber pedagógico.

\section{La pedagogía como saber pedagógico}

En la obra de Foucault ${ }^{164},{ }^{165}$ emergen diversos conceptos (saber, poder, sí mismo, sujeto, subjetividad, formación discursiva, práctica) investigados en campos no pedagógicos, pero Zuluaga los aplica a la pedagogía, considerándola un saber, que no es una dimensión reducida de la episteme o la doxa sino como un espacio abierto, flexible y amplio donde muestra su dinámica el conocimiento, y en este sentido allí se podrían distinguir diversos discursos moviéndose a niveles insospechados, "desde los que apenas empiezan a tener objetos de discurso y prácticas para diferenciarse de otros discursos y especificarse, hasta aquellos que logran una sistematicidad que todavía no obedece a criterios formales"166.

El concepto de saber se contrapone al concepto de conocimiento. Este está más relacionado con la episteme, con el producto obtenido de un proceso investigativo en el que se utilizan métodos científicos especiales, y por tanto su legitimidad es mayor que el rango que podría alcanzar el saber. No obstante, este es más amplio que el conocimiento y rebasa los límites que imponen la ciencia en su concepción clásica.

Basándose en estos criterios, Runge señala que las intencionalidades de un estudio de estas dimensiones no se enmarcan solamente en la búsqueda de un conocimiento concreto, sino que se orienta hacia un saber "en su sentido de dispersión más amplio, por su génesis y por las condiciones de aparición y de emergencia" 167 . Desde esta mirada, la orientación heurística ya no se enfoca solo en el saber sino en el poder que subyace este, y lo más significativo ya no es lo que el saber expresa sino lo que oculta, lo que no dice o lo que dice de manera solapada en lo expresado, es decir, los procedimientos, métodos, condiciones y circunstancias que facilitan el poder que determina y legitima el saber.

\footnotetext{
162 Luis Antonio Mattos, Compendio de didáctica general (Buenos Aires: Kapeluz, 1979), 22.

163 Olga Lucía Zuluaga, op. cit., 2003, p. 71.

164 op. cit.

165 Michel Foucault, Hermenéutica del sujeto (Buenos Aires: FCE, 2009)

166 op. cit. 1987 , p. 40.

167 Andrés Klaus Runge, op. cit., 2015, p. 5.
} 
Zuluaga ${ }^{168}$ distingue el saber pedagógico de la práctica pedagógica. Esta la entiende como un concepto metodológico que indica los modelos pedagógicos que subyacen el rol del profesor, su modo de actuación profesional, su actividad de enseñanza. En cambio el saber pedagógico, aunque también es un concepto metodológico central en su propuesta, expresa los discursos sobre la enseñanza y la educación. Si bien es cierto que estas dos nociones tienen una extraordinaria importancia para comprender la educación y la pedagogía, no pueden evitar las críticas de Runge ${ }^{169}$, quien señala la poca legibilidad de estos conceptos y afirma que no alcanzan el rango de teoría tan necesario para utilizarlos en la investigación educativa o sobre la educación, no obstante, indica que la pedagogía se identifica como saber para poder buscarse a sí misma.

Quiceno también considera que la pedagogía es saber pedagógico, pero cuando es ciencia, cuando tiene la función de "explicar los procedimientos de educación por medios racionales, humanos, activos, lógicos, epistemológicos y sociales" ${ }^{\prime 170}$.

Por otro lado, Zuluaga, Echeverri, Martínez, Restrepo \& Quiceno valoran la pedagogía como una disciplina que "conceptualiza, aplica y experimenta los conocimientos referentes a la enseñanza de los saberes específicos en las diferentes culturas", es decir, la asocian a la didáctica, por cuanto se relaciona con "los procesos de enseñanza propios de la exposición de las ciencias" y con "el ejercicio del conocimiento en la interioridad de una cultura"171. Asimismo, Flórez considera la pedagogía como una disciplina que desarrolla y sistematiza el saber sobre el desarrollo del proceso educativo, en el contexto cultural de la formación social del ser humano. Es una noción referida al discurso o reflexión sobre la educación en tanto proceso de socialización, adaptación y configuración de mundos culturales, es el "saber riguroso sobre la enseñanza, que se ha venido validando y sistematizando en el siglo XX como una disciplina científica en construcción, con su campo intelectual de objetos y metodología de investigación propios, según cada paradigma pedagógico" ${ }^{172}$. Desde esta mirada, la pedagogía es una "disciplina reconstructiva que pretende transformar un saber-como domeñado prácticamente en un saber-qué explícito"173.

Durkheim no consideraba la pedagogía como una ciencia, pero tampoco la consideraba como un arte. "La pedagogía es, pues, algo intermedio entre el arte y la ciencia"174. La pedagogía se aproxima a la ciencia en tanto conjunto de teorías cuyo objeto inmediato es guiar la conducta, pero "no es arte porque no constituye un sistema de prácticas organizadas, sino de ideas relativas a esas

\footnotetext{
168 op. cit.

169 Ídem.

170 op. cit., 2005, p. 76.

171 Olga Lucía Zuluaga et. al., Pedagogía y Epistemología (Bogotá: Magisterio, 2003), 36.

172 op. cit., p. 352.

173 Antanas Mockus, "Presupuestos filosóficos y epistemológicos del privilegio del currículo", en Memorias. Ciclo de conferencias sobre planteamientos y reflexiones alrededor del currículo en la educación superior (Bogotá: ICFES, 1989), 14.

174 op. cit., 2002, p. 65.
} 
prácticas" ${ }^{175}$. La pedagogía en la mirada de este autor podría ser considerada como un saber que no es científico pero tampoco es artístico.

La pedagogía es una de las pocas teorías que más ha soportado una sobreconceptualización sin límites. La proliferación desmedida de conceptos asociados a ella no ha logrado desvanecerla. Ha resistido tantas fundaciones que "cuando sea posible realizar un balance epistemológico de la formación de sus conceptos, rodarán por el suelo todos aquellos ídolos que han vivido a expensas del desconocimiento de las fuentes primarias que han trazado el horizonte conceptual de la pedagogía"176

La pedagogía no es solamente un discurso sobre la enseñanza, sino además "una práctica cuyo campo de explicación es el discurso" 177. Pero una formación discursiva ideologizada que impone su saber pedagógico mediante el poder que otorga ese mismo saber.

Sin lugar a dudas, es impresionante el despliegue teórico, conceptual y metodológico logrado por esta autora, mediante el cual asigna nuevos presupuestos a la pedagogía, la organiza en un nuevo ámbito de saber y prolonga su existencia como disciplina científica desde otras condiciones ${ }^{178}$.

En la concepción de Runge ${ }^{179}$, la postmodernidad y el pluralismo cultural y científico observan a la reflexión pedagógica adecuarse a las condiciones histórico-epistemológicas actuales, precisamente por la decisión de Zuluaga de optar por la pedagogía como un saber pedagógico, sobre todo por las manidas discusiones y cuestionamientos al carácter científico de la pedagogía. Es por ello que los trabajos de Zuluaga ${ }^{180}$ abren un camino histórico-epistemológico importante para pensar la pedagogía en Colombia, por cuanto logra develar y visibilizar la historia del discurso, el saber y las prácticas pedagógicas, desde una dimensión diferente que facilita el debate, al enfrentarse a las posturas objetivistas que obstaculizaban la reflexión amplia sobre la educación y la pedagogía ${ }^{181}$.

Hoyos $^{182}$ considera que la pedagogía de la modernidad está caracterizada como una actividad práctica eminentemente ideológica, con poca o nula intención científica, enmarcada en acciones descriptivas, que repite, reproduce y transmite la normatividad social, el saber que impone el poder del estado o de los emisores del discurso oficialista. De esta manera, la desesperada y rauda asignación del carácter científico de la pedagogía y su ubicación dentro de las ciencias humanas y sociales no es más que una forma solapada de ideología vestida de episteme. Afortunadamente, en Colombia no ha habido una tradición

\footnotetext{
175 op. cit., 2002, p. 65.

176 Olga Lucía Zuluaga, op. cit., 2003, p. 67.

177 Olga Lucía Zuluaga, op. cit., 1979, p. 6.

178 Mario Díaz, El campo intelectual de la educación en Colombia (Cali: Universidad del Valle, 1993)

179 op. cit., 2015.

180 op. cit.

181 Andrés Klaus Runge, óp. cit., 2015.

182 Carlos Ángel Hoyos, et. al., óp. cit.
} 
pedagógica sustentada en la pedagogía científica, de ahí el llamado de Runge ${ }^{183}$ a aprovechar la posibilidad que nos brinda la pedagogía como saber y práctica pedagógicos.

En la postmodernidad que emerge de las cenizas de la pedagogía científica impuesta necesitamos una educación emancipadora como práctica de autoconfiguración reflexiva, intereducación y no pedagogía ideologizada en función de la reificación de los seres humanos dominados y marginados por el discurso manipulador. A propósito, un ejemplo del carácter autoritario de la pedagogía está dado en su consideración como arte de enseñar, reduciéndola a la didáctica.

\section{La pedagogía como arte de enseñar (didáctica)}

Perkins ${ }^{184}$ asocia la pedagogía al arte. Este autor afirma que Pedagogía es una palabra erudita que denota el arte de enseñar. Con este pensamiento reduccionista rebaja la pedagogía al acto de enseñanza, a la didáctica, y confirma la concepción anglosajona de considerar una ciencia de la educación, que no es la pedagogía.

Cuando el profesor le explica algún contenido al estudiante le está demostrando que no puede comprenderlo por sí mismo. "Antes de ser el acto del pedagogo, la explicación es el mito de la pedagogía"185. Esta idea demuestra que en Francia se ha considerado la pedagogía como arte de enseñar, es decir, como didáctica. Asimismo, López ${ }^{186}$ considera que la pedagogía tiene funciones teórico-investigativas y técnico-constructivas. Estudia las regularidades de los procesos de enseñanza y de educación, y proyecta el sistema de enseñanza, basándose en los postulados de otras ciencias pero considerando su propio objeto de estudio como ciencia independiente. Desde esta concepción, la pedagogía cumple una función praxiológica, está limitada a ejecutar una actividad relacionada con la enseñanza. Es preciso señalar la confusión entre la pedagogía y la didáctica, entre la pedagogía como disciplina, teoría y discurso sobre el hecho o fenómeno educativo, y la práctica pedagógica concreta (procesos de enseñanza y aprendizaje).

Pedagogía no es lo mismo que didáctica, enseñanza, aprendizaje o educación. Sin embargo, a veces se confunde con otras ciencias de la educación u otras disciplinas. Durante mucho tiempo en la historia de la educación la pedagogía fue considerada un arte, sin embargo "la pedagogía aspira hoy a un estatuto científico y tiende a presentarse como la ciencia de los métodos de educación"187. Como se aprecia, a veces es confundida también con la didáctica, que estudia los procesos de enseñanza y aprendizaje.

\footnotetext{
183 op. cit., 2015.

184 David Perkins, La escuela inteligente. Del adiestramiento de la memoria a la educación de la mente (Barcelona: Gedisa, 1992)

185 Jacques Ranciére, op. cit., p. 23.

186 op. cit.

187 Luis Not, Las pedagogías del conocimiento (México: FCE, 1979), 12.
} 
A lo largo de la historia de la educación, muchos pedagogos han alertado sobre la sobrevaloración que se hace en ocasiones de las investigaciones pedagógicas experimentales. En este sentido, González advertía: “La pedagogía científica ha exagerado las investigaciones experimentales y ha desatendido la reflexión pedagógica y con ello ha perdido de vista el conjunto de totalidad del pensamiento educacional"188. Con esta afirmación comienzan a cimentarse las bases para una pedagogía no científica pero reflexiva, exegética y simbólica, en el sentido que se preocupa por los imaginarios, representaciones y creencias del ser humano. De esta manera la pedagogía comienza a ser considerada como un discurso y una reflexión sobre la educación.

\section{La pedagogía como reflexión sobre la educación}

A principios del siglo XX, Natorp puntualizó el significado filosófico de la pedagogía, al señalar que "para la fundamentación de la pedagogía no bastan dos partes aisladas de la filosofía, la ética y la psicología, sino la filosofía, entera, en todas sus ramas" 189 . Así asigna un enfoque holístico a la pedagogía y no la limita, como lo hizo Herbart, solo a la ética y a la psicología. En la mirada de Herbart la pedagogía es más ciencia que filosofía. En la mirada de Natorp la pedagogía es más filosofía que ciencia.

Por otro lado, para referirse a la teoría de la educación Foucault utiliza dos nociones muy relacionadas entre sí, la pedagogía como "transmisión de una verdad que tiene por función dotar a un sujeto cualquiera de actitudes, de capacidades, de saberes que antes no poseía y que debería poseer al final de la relación pedagógica" 190 , y la psicagogia como "transmisión de una verdad que no tiene por función dotar a un sujeto de actitudes, de capacidades, sino más bien de modificar el modo de ser de ese sujeto" ${ }^{191}$.

La pedagogía, entendiéndola como noción, está relacionada con la acción desplegada por un ser humano sobre otro con la intencionalidad de lograr algún tipo de aprendizaje. "En la escuela decimos que pedagogía es el saber y la práctica del docente cuyo propósito fundamental es afectar el pensamiento, habilidades y comportamientos de los estudiantes" ${ }^{\prime 192}$.

Ahora bien, Luhmann \& Schorr ${ }^{193}$ no aceptan el enfoque teleológico de la pedagogía. Estos autores hacen férreas críticas a la ontología aplicada a la educación y Luhmann ${ }^{194}$ critica con mucha fuerza la idea de finalidad pedagógica, aludiendo que la pedagogía no puede pretender llevar al ser humano a la perfección porque, ontológicamente hablando, no existe un verdadero ser. Esta

\footnotetext{
188 op. cit., p. 22.

189 op. cit., p. 27.

190 op. cit., 2009, p. 102.

191 op. cit., 2009, p. 102.

192 José Darío Herrera, op. cit., p. 109.

193 op. cit., 1990.

194 op. cit.
} 
idea es el resultado de concebir al ser humano como un sistema autopoiético que se reproduce y configura por y desde sí mismo. Estos pensamientos son contrarios a las concepciones sobre los retos de la educación en la modernidad líquida, esbozados por Bauman ${ }^{195}$.

Luhmann ${ }^{196}$ considera que la pedagogía escolar que aflora en la segunda mitad del siglo XVIII se ve obligada a meditar sobre cómo resolver los problemas del sistema educativo, relacionados con las dificultades de los niños y niñas para asimilar las propuestas organizativas de los profesores. En sus inicios la pedagogía se preocupa solamente por el profesor y sus métodos de enseñanza porque el profesor se dedica a la auto-observación. Esto se debe a que debe observar lo que los estudiantes observan mientras estos lo están observando a él.

Según Bruner, la pedagogía "está metida hasta el cuello en la lucha por los mercados simbólicos, por las distinciones, las recompensas y los premios"197.

El objeto de la pedagogía no es el saber propio de las áreas ni el conocimiento científico. En la perspectiva que ha trabajado Herrera el objeto de estudio de la pedagogía "son los procesos de construcción de significado y no los contenidos fijados de las disciplinas" 198 .

La pedagogía moderna ha girado de manera considerable y se ha orientado hermenéuticamente. Es lo que Bruner ${ }^{199}$ ha denominado el giro interpretativo de la pedagogía, expresado en la concepción de que el pensamiento es la configuración de procesos organizativos y contextualizados de formas de interpretar y comprender el mundo, modalidades inconmensurables, precisamente por su carácter histórico, verificable y revisable.

El giro interpretativo identificado por Bruner es un fenómeno académico que no solo se expresó en la pedagogía sino que se manifestó además en las ciencias naturales, la epistemología, las ciencias sociales, la historia, la literatura $\mathrm{y}$ el teatro.

Este giro hermenéutico de la pedagogía es resbaladizo, podría contribuir a su desmembración. Para no perecer en su intento de desarrollo epistémico, la pedagogía debe tener un determinado grado de solidez, garantizada por su solvencia ontológica, es decir, su liquidez no es completa. No debe ser "una pedagogía demasiado light y acomodaticia al sistema; por tanto, una pedagogía analógica de lo cotidiano tiene que evitarla, pues esa pedagogía líquida se desploma francamente en la equivocidad"200. Pero tampoco debe ser una pedagogía demasiado sólida, cientificista, orientada a la equivocidad. Como se aprecia, Beuchot propone una pedagogía analógica de lo cotidiano, la cual, sin solidificarse "puede ser una pedagogía líquida, como opuesta a la pedagogía

\footnotetext{
195 Zygmunt Bauman, Los retos de la educación en la modernidad líquida (Barcelona: Gedisa, 2008).

196 op. cit.

197 op. cit., 2000, p. 49.

198 op. cit., p. 114.

199 op. cit., 2000.

200 Maurice Beuchot, Hermenéutica analógica, educación y filosofía (Bogotá: Universidad Santo Tomás, 2010), 102.
} 
sólida, pero no puede ser tan líquida que se disuelva" ${ }^{201}$. Debe ser una pedagogía con determinada consistencia.

Bruner $^{202}$ analiza la Pedagogía como la psicología del desarrollo asistido y vaticina que deberá fundirse en el crisol metódico de la elaboración curricular, antes de que como teoría pueda alcanzar su total capacidad descriptiva. Zambrano ${ }^{203}$ considera que la pedagogía "no es la ciencia de la educación, dado que no detenta tal carácter ni por su objeto -el cual es impreciso- ni por la organización institucional y formalización de sus prácticas a través de un diploma" (p. 108). Este autor, parodiando a Levinas, señala que la Pedagogía es Trascendencia y Altura por cuanto ella presupone un juego ético y una responsabilidad debida al Otro.

El punto de partida de la pedagogía es la reflexión sobre la educación. Esta mirada se encuentra en la literatura francesa hacia el año de 1922, como lo ha documentado Zambrano ${ }^{204}$. Por esta fecha se publica la magistral obra Sociología de la Educación, de Emile Durkheim, en la que demuestra que en Francia no existía una definición clara sobre la educación y la pedagogía. Para Durkheim, "la pedagogía ha sido demasiado a menudo una forma de literatura utópica" 205 .

Otros autores como Meirieu ${ }^{206}$ también consideran que la pedagogía no es la ciencia de la educación sino una actividad práctica relacionada con las ciencias de la educación. Postman, citando a Hameline y Piveteau, señala que "si fuese posible en pedagogía establecer verdades 'ciencia cierta', la cosa, a pesar de todo, se sabría [...]. La pedagogía no es, ni mucho menos, la ciencia de la educación. Es una práctica de la decisión que concierne a esta última. La incertidumbre es pues su destino"207.

Para Meirieu la pedagogía no es más que la "reflexión acerca de la educación del niño y, extensión, también, acerca de la educación del adulto" ${ }^{208}$. La pedagogía cuestiona y problematiza los fines de la educación. "La pedagogía, en tanto asume el cuidado del otro, está inscrita en el campo de la educación y, en este contexto, es la expresión compleja de la cultura" ${ }^{209}$. No puede reducirse al ámbito del aprendizaje o de la enseñanza o de la innovación educativa. Su ámbito de influencia es más amplio y profundo. La pedagogía es la razón de ser de la educación, es una reflexión sobre la misma, es su patrocinadora, quien la ampara y defiende. Es su tutora.

Runge, Garcés y Muñoz consideran que la pedagogía es un campo profesional y disciplinar que abarca no solo la idea de pedagogía sino "un conjunto de

\footnotetext{
201 ídem.

202 op. cit., 2012.

203 op. cit., 2006.

204 ídem.

205 op. cit., 1976 , p. 26

206 op. cit.

207 Nicanor Postman, Enseigner c'est résister (París: Le Centurion, 1981), 6.

208 op. cit., 2009, p. 224.

209 Armando Zambrano, op. cit., 2005, p. 136.
} 
pensamientos, reflexiones, discusiones y escritos sobre la praxis educativa (educación) en su sentido amplio y en sus múltiples formas" ${ }^{210}$. La pedagogía para estos autores es una disciplina cuyo objeto de estudio "es el fenómeno educativo en su amplitud y cuya tarea es estudiar, entender, interpretar e influir sobre ese fenómeno bajo sus aspectos particulares y deslindado de otros fenómenos de la vida" ${ }^{211}$.

Quinceno por su parte, afirma que Goethe no estaba interesado en configurar conocimiento científico, no quería generar un saber ni establecer la pedagogía como ciencia, disciplina o saber, porque consideraba la pedagogía como "una cultura abierta, personal, una experiencia que se construye entre el hombre, su ser y el ser de la naturaleza" ${ }^{212}$. En esta misma línea de pensamiento, Wyneken ${ }^{213}$ afirma que el conflicto de conciencia de la pedagogía y su perplejidad tienen un condicionamiento histórico y temporal, por cuanto estamos viviendo en una época de nueva formación y disolución, y este es un fenómeno típico de esta época de transición.

Este es un período histórico de profundas crisis en la educación y en los grandes relatos. La pedagogía como disciplina debe buscar la oportunidad praxiológica de emerger victoriosa del estremecimiento epistémico a que está siendo sometida, y con toda seguridad "será la argumentación epistémica y hermenéutica la que podrá apoyarle, y no las expresiones airadas del voluntarismo subjetivista, o la aporía del objetivismo" ${ }^{214}$.

\section{CONCLUSIÓN}

Como se aprecia al analizar la génesis y evolución de la noción de pedagogía, a lo largo de su historia se han configurado al menos cinco tendencias diferenciadas entre sí: la pedagogía como ciencia de la educación, la pedagogía como una de las ciencias de la educación, la pedagogía como saber pedagógico, la pedagogía como arte de enseñar (didáctica) y la pedagogía como reflexión sobre la educación. Es necesario considerar a la pedagogía como la constelación universal del saber pedagógico configurado por la comunidad académica internacional.

Aún está vigente el controversial debate sobre la pedagogía y las ciencias de la educación. No hay consenso en la comunidad académica internacional sobre la configuración epistémica de la pedagogía. Las concepciones y criterios dependen de las particularidades de estas ciencias o disciplinas en cada país. Mientras que en Colombia la pedagogía es un saber pedagógico o una reflexión

\footnotetext{
210 op. cit., p. 214.

211 ídem.

212 op. cit., 2005 , p. 79.

213 Gilbert Wyneken, "Las antinomias centrales de la Pedagogía", en Ideas pedagógicas del siglo XX, ed. Luis Luzuriaga (Buenos Aires: Losada, 2010), 53-62

214 Carlos Ángel Hoyos, et. al. op. cit., p. 8.
} 
sobre la educación, en Cuba la pedagogía es considerada una ciencia que estudia la educación, en Estados unidos se habla de la Ciencia de la Educación, en singular, pero no se utiliza la noción de pedagogía con la connotación de ciencia de la educación. Asimismo, en Francia se habla de las Ciencias de la Educación, en plural, y en Alemania de habla de la Ciencia de la Educación, pero entendiendo como esta a la Pedagogía.

No obstante, la pedagogía es una disciplina independiente que se ha venido configurando desde hace más de dos siglos. Su evolución y desarrollo está relacionado con las configuraciones sociales, políticas, económicas, filosóficas e incluso ideológicas. La pedagogía siempre debe estar pendiente y atenta cuidando y conservando las intenciones formativas del educador. Es por ello que debe seguir siendo una ciencia autónoma o una teoría reflexiva del sistema educativo, con el fin de "proteger al símbolo que hace reconocible qué pertenece al sistema y qué no" 215 .

Luhmann considera que las personas son sagradas para la pedagogía, sin embargo, un análisis profundo, minucioso y detallado de su configuración epistémica "pone de manifiesto la mentira vital de la pedagogía: alabar las buenas intenciones y celebrar las configuraciones del individuo como su libertad" ${ }^{216}$.

Por consiguiente, si la pedagogía quiere (y quiere) emerger con vida de sus cenizas, debe desprenderse con urgencia de los rasgos positivistas que la azotan. Si la pedagogía quiere (y quiere) resucitar, debe abandonar de inmediato el lenguaje empírico-analítico (evocando a Habermas ${ }^{217},{ }^{218}$ ) que la aprisiona. Si la pedagogía quiere (y quiere) erigirse victoriosa y salir de los escombros del paradigma físico-naturalista, debe ignorar las nociones de las mal llamadas ciencias exactas y puras (matemática, física), como por ejemplo la noción de Campo.

No existe un campo pedagógico, la pedagogía no es un espacio, no es un objeto, no es sustancia. No podemos (aunque queramos) medir la efectividad de la pedagogía. Esta no es tangible, es inconmensurable. Un campo puede ser ubicado, distinguirse, tocarse, tasarse y medirse, la pedagogía no, y por eso no debe ser considerada un campo, sino una configuración conceptual comprensiva. No existe un campo pedagógico, existen configuraciones pedagógicas. De esta manera, la pedagogía debe intentar salvarse de la pedagogía. Debemos evitar su homicidio en el discurso de aquellos que, conscientes o no, intencionalmente o no, le causan daño con su nociva narración. No obstante, seguimos en el mismo lugar y no encontramos salida: no sabemos guiar el cortejo fúnebre de lo pedagógico, de la pedagogía misma, implicada también en la depresión que nos acecha o nos asalta a causa de la irreversible crisis de la educación. Y es precisamente por un recrudecimiento artificial de lo pedagógico por lo que intentamos escabullirnos. Esto, sin lugar a dudas, acabará produciendo y engendrando la pedagogía. Renacerá de sus propias cenizas.

\footnotetext{
215 Niklas Luhmann, op. cit., 1996, p. 150.

216 Niklas Luhmann, op. cit., 1996, p. 158.

217 Jürgen Habermas, Conocimiento e interés (Madrid: Taurus, 1968)

218 Jürgen Habermas, Tres enfoques de investigación en ciencias sociales. Comentarios a propósito de conocimiento e interés (Bogotá: Universidad Nacional, 1978)
} 
Por una torsión inesperada, de súbito, por una ironía científica y epistémica, o quizá doxática, será de la muerte de lo educativo de donde surgirá la pedagogía, así como vaticinó Baudrillard ${ }^{219}$ la aparición del socialismo a partir de la muerte de lo social, el poder y lo real.

La pedagogía es un referente imaginario. Esto no significa que no exista sino que ha dejado de haber una configuración representativa posible de ella. De allí la afirmación de Baudrillard que recoge Runge de que "las teorías pedagógicas han perdido su conexión con la realidad y los signos se han convertido en sus propios simulacros; simulan la realidad. La hiperrealidad en pedagogía resulta de las exigencias de orientarse más hacia la praxis por parte de la academia"220.

\section{REFERENCIAS}

Addine, Fátima. Didáctica y optimización del proceso de enseñanza-aprendizaje. La Habana: IPLAC, 1998.

Addine, Fátima. Didáctica. Teoría y práctica. Ciudad de La Habana: Pueblo y Educación, 2004.

Aguayo, Alfredo. Filosofía y nuevas orientaciones de la educación. La Habana: Cultural, 1933.

Aguayo, Alfredo. Pedagogía. La Habana: La Moderna Poesía, 1927.

Álvarez de Zayas, Carlos. La escuela en la vida. La Habana: Félix Varela, 1992.

Álvarez de Zayas, Rita Marina. Hacia un currículum integral y contextualizado. La Habana: Academia, 1997.

Baudrillard, Jean. Cultura y Simulacro. Barcelona: Kairós, 2012.

Bauman, Zygmunt. Los retos de la educación en la modernidad líquida. Barcelona: Gedisa, 2008.

Bedoya, José Iván. Epistemología y Pedagogía. Ensayo histórico sobre el objeto y método pedagógicos. Bogotá: ECOE, 2013.

Beuchot, Maurice. Hermenéutica analógica, educación y filosofía. Bogotá: Universidad Santo Tomás, 2010.

Bisquerra, Rafael. Modelos de la Orientación psicopedagógica. Barcelona: Boixareu Universitaria, 1998.

Bourdieu, Pierre. Razones prácticas. Sobre la teoría de la acción. Barcelona: Anagrama, 2007. Bruner, Jerome. La educación, puerta de la cultura. Madrid: Visor, 2000.

Bruner, Jerome. La importancia de la educación. Barcelona: Paidós, 2012.

Carreras, Carlos. Aprender a formar. Educación y procesos formativos. Barcelona: Paidós, 2003.

Carvajal, Gilberto. "La lógica del concepto de pedagogía". Revista Iberoamericana de Educación. OEI, 2010.

Civarolo, María. Mercedes. La idea de la Didáctica. Bogotá: Magisterio, 2011.

Coll, Cesar. Psicología y Currículum. Buenos Aires: Paidós, 1994.

219 Jean Baudrillard, Cultura y Simulacro (Barcelona: Kairós, 2012).

220 Andrés Klaus Runge, óp. cit., 2008, p. 197. 
Colom Cañellas, Antonio; José Luis Bernabéu Rico, Emilia Domínguez Rodríguez y Jaume Sarramona. Teorías e instituciones contemporáneas de la educación. Barcelona: Ariel, 2008.

Comenio, Juan Amos. Didáctica Magna. Madrid: Akal, 2012.

De la Torre, Carlos. Manual para los exámenes de maestros. La Habana: La Moderna Poesía, 1904.

De Zubiría, Julián. Los modelos pedagógicos. Bogotá: Fundación Alberto Merani, 1994.

De Zubiría, Julián. Los modelos pedagógicos. Hacia una pedagogía dialogante. Bogotá: Magisterio, 2011.

De Zubiría, Miguel y Julián De Zubiría. Fundamentos de Pedagogía Conceptual. Bogotá: Plaza \& Janés, 2002.

De Zubiría, Miguel. Formar, no solo educar. Bogotá: Fundación Internacional de Pedagogía Conceptual, 2008b.

De Zubiría, Miguel. Las teorías de Pedagogía Conceptual. Bogotá: Fundación Internacional de Pedagogía Conceptual, 2008c.

De Zubiría, Miguel. Los fines y el método de la Pedagogía Conceptual. Bogotá: Fundación Internacional de Pedagogía Conceptual, 2008a.

De Zubiría, Miguel. Pedagogía Conceptual. Desarrollos filosóficos, pedagógicos y psicológicos. Bogotá: Fundación Internacional de Pedagogía Conceptual, 2004.

De Zubiría, Miguel. Pedagogías del siglo XXI: Mentefactos I. El arte de pensar para enseñar y de enseñar para pensar. Bogotá: Fundación Internacional de Pedagogía Conceptual, 2006.

Deleuze, Gilles. Qué es la filosofía. Barcelona: Anagrama, 1999.

Dewey, John. Mi credo pedagógico. León: Universidad de León, 1997.

Dewey, John. Cómo pensamos. Barcelona: Paidós, 1989.

Dewey, John. Democracia y educación. Una introducción a la filosofía de la educación. Madrid: Morata, 1916.

Dewey, John. Experiencia y educación. Madrid: Biblioteca Nueva, 2003.

Dewey, John. La ciencia de la educación. Buenos Aires: Losada, 1964.

Dewey, John. La escuela y el niño. Madrid: Ediciones de la Lectura, 1926.

Díaz, Mario. "Pedagogía, discurso y poder". En: M. Díaz \& J. Muñoz (editores). Pedagogía, discurso y poder. Bogotá: Corprodic, 1990, pp. 39-67.

Díaz, Mario. El campo intelectual de la educación en Colombia. Cali: Universidad del Valle, 1993.

Díaz-Barriga, Ángel. Pensar la didáctica. Buenos Aires: Amorrortu, 2012.

Dilthey, Winthel. Ideas acerca de una psicología descriptiva y analítica. Obras completas. Vol. 6. México: FCE, 1951.

Dilthey, Winthel. Introducción a las ciencias del espíritu. Madrid: Alianza, 1980.

Durkheim, Emile. Educación y sociología. Bogotá: Babel, 1976.

Durkheim, Emile. La educación moral. Madrid: Trotta, 2002.

Echeverri, José Antonio. Paradigmas y conceptos en educación y pedagogía. Bogotá: Siglo del Hombre, 2015.

Flórez, Rafael. Pedagogía del conocimiento. Bogotá: McGraw-Hill, 1994.

Foucault, Michel. Hermenéutica del sujeto. Buenos Aires: FCE, 2009.

Foucault, Michel. Las palabras y las cosas. Una arqueología de las ciencias humanas. México:

Siglo XXI, 1966. 
Fuentes, Homero e Ilsa Álvarez. Dinámica del proceso docente educativo de la educación superior. Santiago de Cuba: CEES “Manuel F. Gran”. Universidad de Oriente, 1998.

García, Juan. Teoría de la educación. Madrid: Anaya, 1984.

González, David. Introducción a la filosofía de la educación. La Habana: Cultural, 1946.

Habermas, Jürgen. Conocimiento e interés. Madrid: Taurus, 1968.

Habermas, Jürgen. Teoría de la acción comunicativa. Madrid: Trotta, 2010.

Habermas, Jürgen. Tres enfoques de investigación en ciencias sociales. Comentarios a propósito de conocimiento e interés. Bogotá: Universidad Nacional, 1978.

Herbart, Johan Friedrich. Pedagogía General derivada del fin de la educación. Madrid: La Lectura, 1935.

Herrera, José Darío. Pensar la educación, hacer investigación. Bogotá: Universidad de la Salle, 2013.

Hoyos, Carlos Ángel et. al. Epistemología y objeto pedagógico. ¿Es la pedagogía una ciencia? México: UNAM. Instituto de investigaciones sobre la Universidad y la Educación (IISUE), 2010.

Hoyos, Gilberto. Filosofía de la Educación. Apuntes de su último seminario de doctorado. Bogotá: Siglo del Hombre, 2013.

Hubert, Rafael. Tratado de pedagogía general. París: s.e., 1965.

Kant, Inmanuel. Pedagogía. Madrid: Akal, 1803.

Kenneth, Rafael. La revolución de la enseñanza. La Habana: Edición Revolucionaria, 1975.

Labarrere, Guillermina y Gladys Valdivia. Pedagogía. La Habana: Pueblo y Educación, 1988.

Lemus, Luis Ángel. Pedagogía. Temas fundamentales. Buenos Aires: Kapeluz, 1969.

López, Josefina. El carácter científico de la pedagogía en Cuba. Ciudad de la Habana: Pueblo y Educación, 1996.

Luhmann, Niklas y Karl Eberhard Schorr. El sistema educativo (problemas de reflexión). México: Universidad de Guadalajara, 1993.

Luhmann, Niklas y Karl Eberhard Schorr. Presupuestos estructurales de una pedagogía reformista. Análisis sociológicos de la pedagogía moderna. Revista Educación, No. 291 (1990): 55-79.

Luhmann, Niklas. Teoría de la sociedad y pedagogía. Buenos Aires: Paidós, 1996.

Luzuriaga, Luis. Pedagogía. Buenos Aires: Lozada, 1984.

Martínez, Ángel. "Figuras contemporáneas del maestro en América Latina". En: Álvarez, A. \& Martínez, A. (Comps.). Treinta años del Grupo Historia de la Práctica Pedagógica. Bogotá: Magisterio, 2010.

Mattos, Luis Antonio. Compendio de didáctica general. Buenos Aires: Kapeluz, 1979.

Medina, Ángel y Francisco Salvador. Didáctica general. Madrid: Prentice-Hall, 2002.

Meirieu, Pilippe. Aprender, sí. Pero ¿cómo? Barcelona: Octaedro, 1992.

Meirieu, Pilippe. Carta a un joven profesor. Por qué enseñar hoy. Barcelona: Grao, 2005.

Meirieu, Pilippe. La opción de educar: Ética y Pedagogía. Barcelona: Octaedro, 2001.

Mendoza, Carlos. La pedagogía como ciencia: notas para un debate. Caracas: Universidad Pedagógica Experimental Libertador (UPEL), 2015.

Mialaret, Gilbert. Ciencias de la educación. Barcelona: Oikos-Tau, 1976.

Mialaret, Gilbert. Introducción a las ciencias de la educación. Ginebra: UNESCO, 1985. 
Mockus, Antanas. "Presupuestos filosóficos y epistemológicos del privilegio del currículo". En: Memorias. Ciclo de conferencias sobre planteamientos y reflexiones alrededor del currículo en la educación superior. Bogotá: ICFES, 1989.

Monereo, Carlos. Estrategias de enseñanza y aprendizaje. México: Fondo Mixto de Cooperación Técnica y Científica, 1988.

Natorp, Paul. Curso de Pedagogía. Madrid: s/e, 1915.

Not, Luis. Las pedagogías del conocimiento. México: FCE, 1979.

Perkins, David. La escuela inteligente. Del adiestramiento de la memoria a la educación de la mente. Barcelona: Gedisa, 1992.

Perrenaud, Phillie. Construir competencias desde la escuela. Santiago de Chile: DolmenOcéano, 1999.

Pestalozzi, Juan Enrique. Cómo Gertrudis enseña a sus hijos. México: Porrúa, 1801.

Postman, Nicanor. Enseigner c'est résister. París: Le Centurion, 1981.

Prieto, Blas. Principios generales de la educación. Caracas: Monte Ávila, 1985.

Quiceno, Humberto. “Michel Foucault, ¿pedagogo?” En: Zuluaga, O. L. et. al. Foucault, la Pedagogía y la Educación. Pensar de otro modo. Bogotá: Magisterio, 2005.

Quiceno, Humberto. "Sujeto y subjetividad en las ciencias de la educación en Colombia. El docente, el profesional y el intelectual". En: J. A. Echeverri et. al. Paradigmas y conceptos en educación y pedagogía. Bogotá: Siglo del Hombre, 2015.

Ranciére, Jacques. El maestro ignorante. Barcelona: Laertes, 1987.

Ríos, Raúl. Las ciencias de la educación en Colombia. 1926-1954. Bogotá: Magisterio, 2008.

Rousseau, Juan Jacobo. Emilio o De la Educación. Madrid: Alianza, 2011.

Runge, Andrés Klaus. Ensayos sobre Pedagogía Alemana. Bogotá: Universidad Pedagógica Nacional, 2008.

Runge, Andrés Klaus. “Una epistemología histórica de la pedagogía: El trabajo de Olga Lucía Zuluaga". Revista de Pedagogía. Escuela de Educación. Universidad Central de Venezuela, 2015.

Runge, Andrés Klaus., Juan Fernando Garcés y David Antonio Muñoz. “La pedagogía como campo profesional y disciplinar. Lugar estratégico para enfrentar las tensiones entre el reconocimiento científico, la profesionalidad y la regulación socio-estatal de la profesión docente". En: J. A. Echeverri et. al. Paradigmas y conceptos en educación y pedagogía. Bogotá: Siglo del Hombre, 2015.

Saavedra, Raúl y Miguel Suárez. Diccionario de pedagogía. México: Pax, 2001.

Santos, Miguel Ángel. La escuela que aprende. Madrid: Morata, 2000.

Simmel, George. Pedagogía escolar. Barcelona: Gedisa, 2008.

Solari, Manuel. Pedagogía General. Buenos Aires: El Ateneo, 1966.

Soto Arango, Diana y María Isabel Lafuente Guantes. Autonomía y modelos universitarios en América Latina y España, Tunja: Universidad de León-Búhos Editores, 2007.

Soto Arango, Diana; Jesús Paniagua; José Rubens Lima Jardilino y María Cristina Vera. Educadores en América Latina y el Caribe de la Colonia al siglo XIX-XX. Tunja: Ediciones Doce Calles, 2011.

Soto Arango, Diana. La Universidad en el Periodo colonial. Educadores criollos neogranadinos. Tunja: Ediciones Doce Calles, 2011.

Tamayo, Luis Antonio. “Tendencias dela pedagogía en Colombia”. Revista Latinoamericana de Estudios Educativos. Vol. 3 (1), enero-junio, 65-76, 2007.

Titone, Raúl. Metodología Didáctica. Buenos Aires: Rialp, 1985. 
Traveset, Miguel. La pedagogía sistémica. Fundamentos y práctica. Barcelona: Grao, 2007. Trejo, Karina. Metodología del proceso enseñanza-aprendizaje. México: Trillas, 2012.

Wyneken, Gilbert. "Las antinomias centrales de la Pedagogía". En: Luzuriaga, L. Ideas pedagógicas del siglo XX. Buenos Aires: Losada. pp. 53-62, 2010.

Zambrano, Armando. Didáctica, pedagogía y saber. Bogotá: Magisterio, 2005.

Zambrano, Armando. Los hilos de la palabra. Pedagogía y Didáctica. Bogotá: Magisterio, 2006.

Zambrano, Armando. Pedagogía, educabilidad y formación de docentes. Cali: Nueva Biblioteca Pedagógica, 2001.

Zuluaga, Olga Lucía; Ángel Echeverri; Antonio Martínez; Saúl Restrepo y Humberto Quiceno. "Educación y Pedagogía: una diferencia necesaria". En: O. L. Zuluaga et. al. Pedagogía y Epistemología. Bogotá: Magisterio, 2003.

Zuluaga, Olga Lucía. "Educación y pedagogía". Revista Educación y Cultura. Bogotá, 1988.

Zuluaga, Olga Lucía. “El pasado presente de la pedagogía y la didáctica”. En: O. L. Zuluaga et. al. Pedagogía y Epistemología. Bogotá: Magisterio, 2003.

Zuluaga, Olga Lucía. “El saber pedagógico: Experiencias y conceptualizaciones". En: Echeverri, J. A. (ed.). Encuentros pedagógicos transculturales: Desarrollo comparado de las conceptualizaciones y experiencias pedagógicas en Colombia y Alemania, pp. 81-88. Medellín: Universidad de Antioquia, 1999.

Zuluaga, Olga Lucía. “El saber pedagógico: experiencias y conceptualizaciones”. En: Encuentros pedagógicos transculturales: desarrollo comparado de las conceptualizaciones y experiencias pedagógicas en Colombia y Alemania. Centro Consolidado de Investigaciones Educativas y Pedagógicas. Medellín: Editorial Marín Vieco. pp. 81-88, 2001.

Zuluaga, Olga Lucía. Foucault, la pedagogía y la educación. Pensar de otro modo. Bogotá: Magisterio, 2005.

Zuluaga, Olga Lucía. Hacia una historia de la práctica pedagógica colombiana en el siglo XIX. Medellín: Universidad de Antioquia, 1979.

Zuluaga, Olga Lucía. Pedagogía e historia. La historicidad de la pedagogía. La enseñanza, un objeto de saber. Bogotá: Foro Nacional por Colombia, 1987.

Zuluaga, Olga Lucía. Pedagogía y Epistemología. Bogotá: Magisterio, 2003.

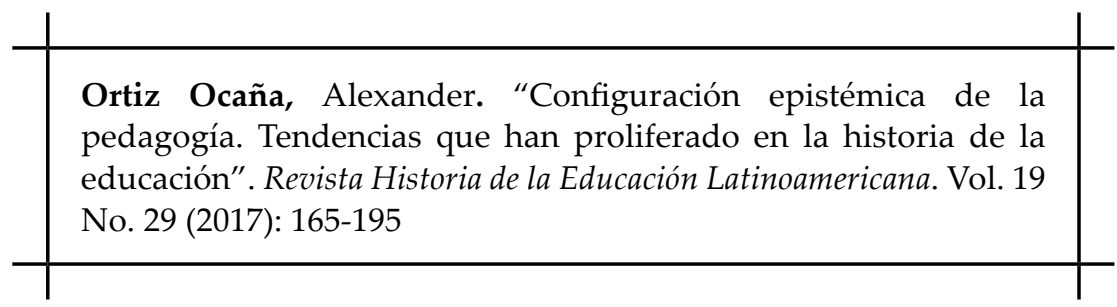

